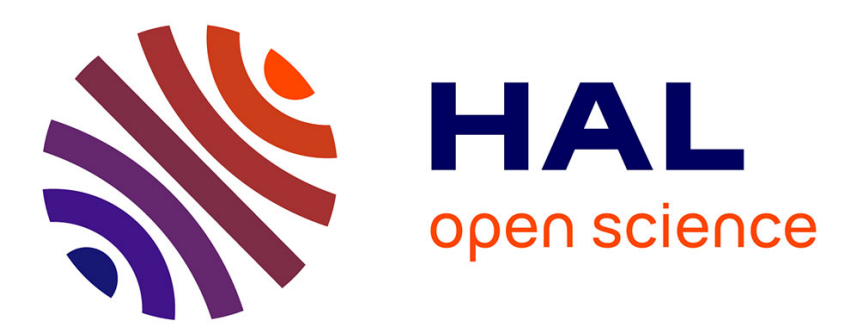

\title{
Laser generation of nano-bumps below 2nm height on silicon for debris-free marking/patterning
}

\author{
A Pena, Z B Wang, D J Whitehead, R Lloyd, L Li
}

\section{To cite this version:}

A Pena, Z B Wang, D J Whitehead, R Lloyd, L Li. Laser generation of nano-bumps below 2nm height on silicon for debris-free marking/patterning. Journal of Physics D: Applied Physics, 2010, 43 (11), pp.115302. 10.1088/0022-3727/43/11/115302 . hal-00569555

\section{HAL Id: hal-00569555 \\ https://hal.science/hal-00569555}

Submitted on 25 Feb 2011

HAL is a multi-disciplinary open access archive for the deposit and dissemination of scientific research documents, whether they are published or not. The documents may come from teaching and research institutions in France or abroad, or from public or private research centers.
L'archive ouverte pluridisciplinaire HAL, est destinée au dépôt et à la diffusion de documents scientifiques de niveau recherche, publiés ou non, émanant des établissements d'enseignement et de recherche français ou étrangers, des laboratoires publics ou privés. 


\title{
Laser generation of nano-bumps below $2 \mathrm{~nm}$ height on silicon for debris-free marking/patterning
}

\author{
A Pena, Z B Wang, D J Whitehead, R Lloyd and L Li \\ Laser Processing Research Centre, School of Mechanical, Aerospace and Civil \\ Engineering, University of Manchester, Sackville Street, Manchester, M60 1QD, \\ United Kingdom \\ E-mail: Ana.Pena@postgrad.manchester.ac.uk
}

\begin{abstract}
By rapidly scanning a $532 \mathrm{~nm}$ diode pumped $\mathrm{Nd}: \mathrm{YVO}_{4}$ laser beam at nano-second pulses and below the ablation threshold, a uniform array of nano-bumps of less than $2 \mathrm{~nm}$ in height (diameter of around $20 \mu \mathrm{m}$ ) has been generated on a ptype $<100>\mathrm{Si}$ wafer. This height is two orders of magnitude lower than previously reported values. They were generated at 30,000 bumps per second. The effect of laser fluence (energy density) and scanning speed on the characteristics of the nanobumps was investigated and the wettability of the laser nano-textured surfaces was examined. The mechanisms of nano-bump formation are discussed. Also presented are the application of the technique for debris free, invisible marking/texturing of silicon and the recognition of such marks/patterns.
\end{abstract}

\section{Introduction: Laser marking on Silicon}

Laser marking of crystalline silicon is a well established process with more than 40 years of applications in the semiconductor industry. Marking of electronic components, wafers, integrated circuits and other items made of this widely used material is of importance to the manufacturers because it allows for information identification, serialization, traceability, copyrighting, and even for decoration [1].

Laser marking of silicon started with "Hard Marking" technology which consisted of laser marks of 5-20 $\mu \mathrm{m}$ depth, fairly visible and durable but with a significant amount of debris around them. Such marks became incompatible with the manufacturing process as the demand for smaller devices increased. This required a new technology by which splatter, debris and depth could be diminished to a minimum. "Soft Marking" by diode pumped solid state (DPSS) lasers was then introduced (height to width aspect ratio of marks $~ 0.01$ ), followed by "Super Soft Marking" (depth of marks $~ 2.6 \mu \mathrm{m}$ ) in which debris generation was 
entirely eliminated [2]. However, the drive to achieve smaller feature sizes, larger output and reduced costs has pushed the development of new marking techniques towards the nano-scale. Micro-peak formation on crystalline silicon [3] has been reported as a feasible, novel marking technology. By directing a Nd:YAG laser beam to a programmable LCD mask, a square array pattern is projected onto a silicon surface. Micro peaks obtained after the laser irradiation exhibit a size of $3.6 \times 3.6 \mu \mathrm{m}^{2}$, a period of $4.5 \mu \mathrm{m}$ and a height of $0.3 \mu \mathrm{m}$. They are claimed to be easily readable under simple lightening due to their depth to width aspect ratio which under correct laser parameters can be set to 0.15 . The aspect ratio in conventional laser marking is a very important feature because it determines the visibility of each mark given by the contrast between bright and dark parts when subjected to some sort of lightening.

Even smaller laser-fabricated features such as smooth craters on $<100>$ silicon (depth of 35 $\mathrm{nm}$ and diameter of $10 \mu \mathrm{m}$ ) have already been demonstrated [4]. Such structures were claimed to be oxide-free after being processed by $8 \mathrm{~ns}$ pulses from a Nd:YAG laser $(\lambda=532$ $\mathrm{nm}$ ) with a fluence of $3 \mathrm{~J} / \mathrm{cm}^{2}$. Such surface modification was attributed to thermal melting and a thermo/chemo-capillary flow. Similar topography changes in the nanometre scale have been obtained in Polyimide [5]. Depending on the laser fluence applied, three regimes were identified: holes (depth of $163 \mathrm{~nm}$ ), humps (height of $17 \mathrm{~nm}$ ) having a small dip at the top (depth of $7 \mathrm{~nm}$ ), and bumps (height of $21 \mathrm{~nm}$ ). Formation mechanisms of the last two topographies were attributed to amorphization of the material, thermal or non-thermal fragmentation of the polymer chains and plastic deformations due to residual stresses introduced at elevated temperatures.

In this paper, uniform arrays of nano-bumps of less than $2 \mathrm{~nm}$ height (diameter of around 20 $\mu \mathrm{m})$ have been demonstrated on a silicon wafer surface. This height value is two orders of magnitude lower than the above reported values for laser marking applications. The effect of laser fluence and scanning speed on the characteristics of the nano-bumps is reported along with the wettability of the laser nano-textured surfaces. The nano-bumps formation mechanism (aspect ratio of 5(10) $)^{-5}$ and height of 1-2 $\mathrm{nm}$ ) is investigated.

\section{Laser Processing Experimental Procedure}

\subsection{Laser Marking}

Pulsed laser irradiation of p-type, single-crystal $\mathrm{Si}<100>$ (boron doped and resistivity of 1-10 $\Omega \cdot \mathrm{cm}$ ) was carried out by means of a diode pumped $\mathrm{Nd}: \mathrm{YVO}_{4}$ laser system (Laservall Violino, wavelength of $\lambda=532 \mathrm{~nm}$, pulse duration of $\tau=8 \mathrm{~ns}$, and a repetition rate of 30 $\mathrm{kHz}$ ) with a computer controlled 3 axis galvanometer beam scanner. 
The substrate surface was scanned by a Gaussian laser beam having an elliptical shape. Measurement of the ablation sites using optical microscopy led to the following spot dimensions: $50 \mu \mathrm{m}$ along the minor axis and $80 \mu \mathrm{m}$ along the major axis. Fluence values on this paper were based on such measurements.

When controlling the intensity of the Gaussian beam, a low fluence of $0.72 \mathrm{~J} / \mathrm{cm}^{2}$ resulted in uniform structures of only $1 \mathrm{~nm}$ in height and $\sim 20 \mu \mathrm{m}$ in width. Processing parameters such as power and scanning speed were varied in order to obtain marks that could not be easily detected unless they were exposed to a difference in temperature with water/moisture condensation.

It was found that laser processing at a fluence of $0.72 \mathrm{~J} / \mathrm{cm}^{2}$, repetition rate of $30 \mathrm{kHz}$ and a scanning speed of $1 \mathrm{~m} / \mathrm{s}$, resulted in very shallow marks only perceptible to the eye after some minutes of being stored in a cold box at $0^{\circ} \mathrm{C}$ or when the surface at $21^{\circ} \mathrm{C}$ is exposed to warm vapour (e.g. at $36-37{ }^{\circ} \mathrm{C}$ ). A single pulse per spot was necessary to achieve a nano-bump structure formation.

Considering the aforementioned laser parameters, an area corresponding to $1 \mathrm{~cm}^{2}$ was processed by following a linear scanning regime to cover the whole surface with nano-bumps. Hatch distance between scanning lines was adjusted to $25 \mu \mathrm{m}$. In this way, a regular square array of the structures was formed. Total processing time for this region was about 4 seconds. Moreover, arbitrary shapes (such as letters and spirals) made of these nano-bumps were created and seen without the need of any special lightening or lenses.

\section{Results}

\subsection{Topographical and morphological characteristics}

Topography and morphology of the nano-bumps were examined with the aid of a high resolution $(0.1 \mathrm{~nm}$ in the z-axis) white light interferometer (Wyko NT1100) and a scanning electron microscope (Hitachi S-3400N). Initially, a bare and clean silicon sample was analyzed to determine its average roughness to be $R_{a}=3.31 \mathrm{~nm}$, as seen in Fig. 1(a). Then, different laser fluences were used to determine the threshold for topography modification at a fixed repetition rate of $30 \mathrm{kHz}$ and a scanning speed of $1 \mathrm{~m} / \mathrm{s}$.

The first signs of structuring (i.e. $1 \mathrm{~nm}$ high bumps emerging from the laser treated area) appeared when the fluence was $0.54 \mathrm{~J} / \mathrm{cm}^{2}$. However, the obtained structures were not organized in a uniform array. When laser fluence increases to $0.72 \mathrm{~J} / \mathrm{cm}^{2}$, a regular array of well defined bumps was obtained as shown in figure 1(b). 

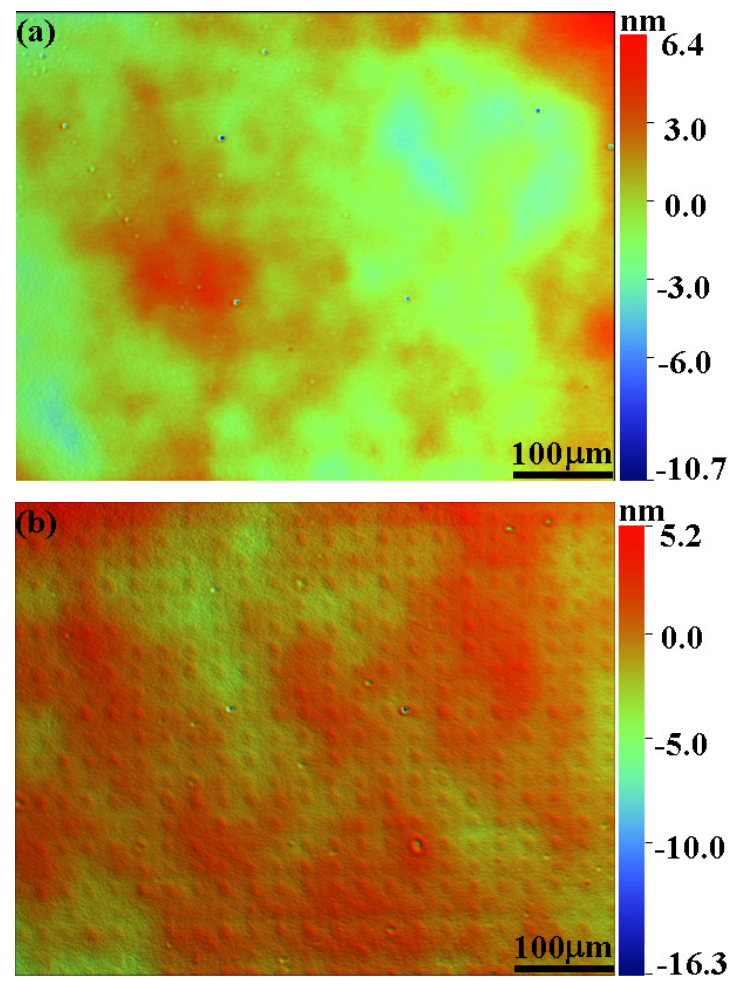

Figure 1. White light interferometer (Wyko NT1100) images of silicon sample surface (a) before laser processing and (b) after laser processing (nano-bumps on top). The used laser fluence was $0.72 \mathrm{~J} / \mathrm{cm}^{2}$.

From the height profiles in figure 2(a) and (b), it was determined that such bumps have a diameter of $\sim 20 \mu \mathrm{m}$, a height of $\sim 1 \mathrm{~nm}$ and period of $\sim 25 \mu \mathrm{m}$.
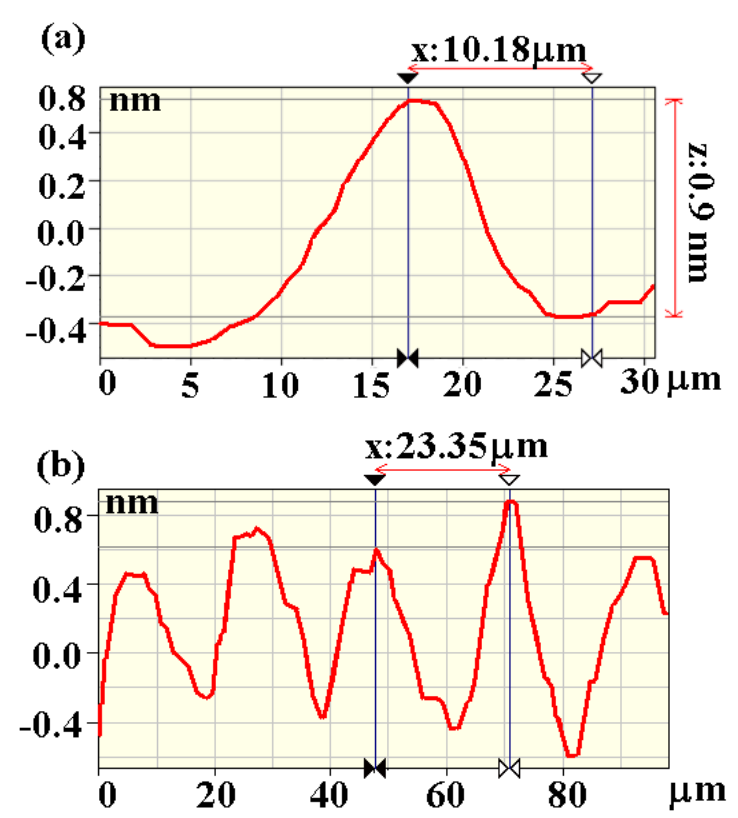

Figure 2. Typical height profiles (Wyko NT1100) of nano-bumps fabricated at laser fluence of 0.72 $\mathrm{J} / \mathrm{cm}^{2}$, showing (a) a radius of $\sim 10.2 \mu \mathrm{m}$ and height of $\sim 1 \mathrm{~nm}$; (b) nano-bumps period of $\Lambda=23 \mu \mathrm{m}$.

An increment in the fluence to $0.83 \mathrm{~J} / \mathrm{cm}^{2}$ generated a random mixture of bumps and craters in the same laser treated area, as seen in figure 3 (a). For bumps, the diameter, height and 
periodicity remained almost the same as in figure 2 . The craters were around $3.5 \mathrm{~nm}$ in depth and $\sim 25 \mu \mathrm{m}$ in diameter (including a small rim around them) in figure $3 \mathrm{~b}$.

With a subsequent increase in fluence to $0.94 \mathrm{~J} / \mathrm{cm}^{2}$, bumps completely vanished from the surface and were replaced solely by craters (figure $3 b$ ). The height profile of such craters is shown in figure $4(a)$ and (b).
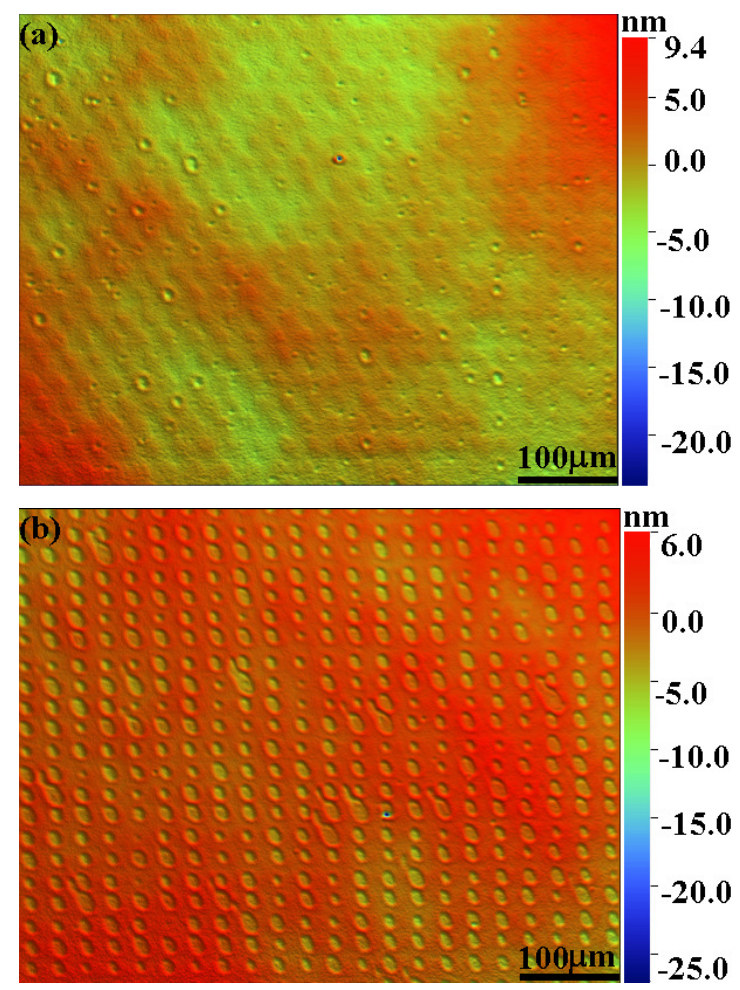

Figure 3. White light interferometer (Wyko NT1100) images of (a) a combination of craters and bumps on silicon sample surface after laser processing at a fluence of $0.83 \mathrm{~J} / \mathrm{cm}^{2}$; (b) craters formed at a laser fluence of $0.94 \mathrm{~J} / \mathrm{cm}^{2}$. 

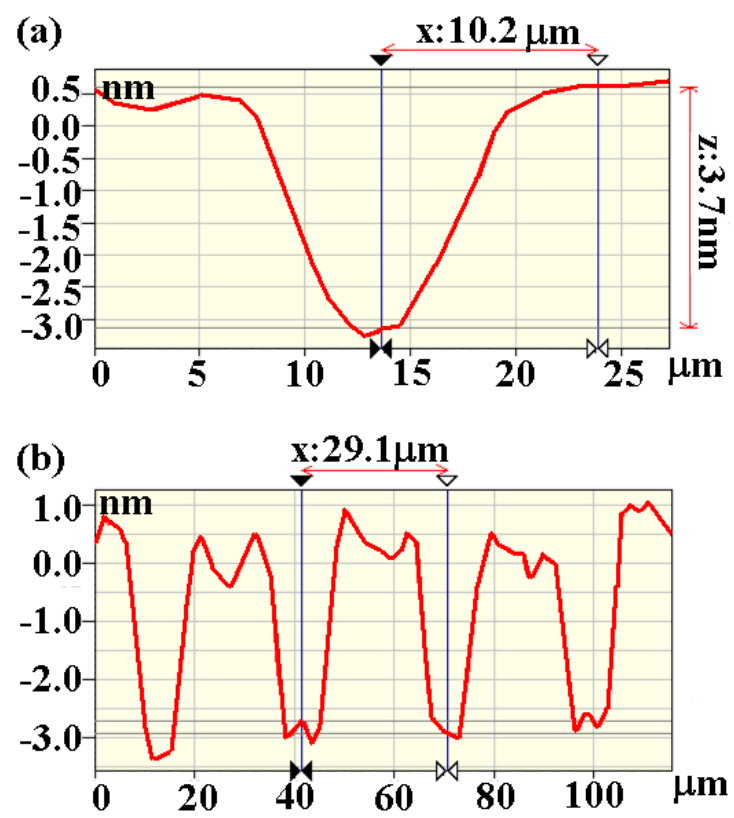

Figure 4. Typical depth profiles of craters generated on silicon surface at a laser fluence of $0.94 \mathrm{~J} / \mathrm{cm}^{2}$, showing (a) radius of $\sim 10.2 \mu \mathrm{m}$ and diameter of $\sim 3.7 \mathrm{~nm}$; (b) craters period of $\Lambda=29 \mu \mathrm{m}$.

Figure 5 summarizes the dependence of structure height (including bumps and craters) as a function of laser fluence. A noticeable amount of debris around the crater structures is observed when the laser fluence is set above $1.5 \mathrm{~J} / \mathrm{cm}^{2}$.
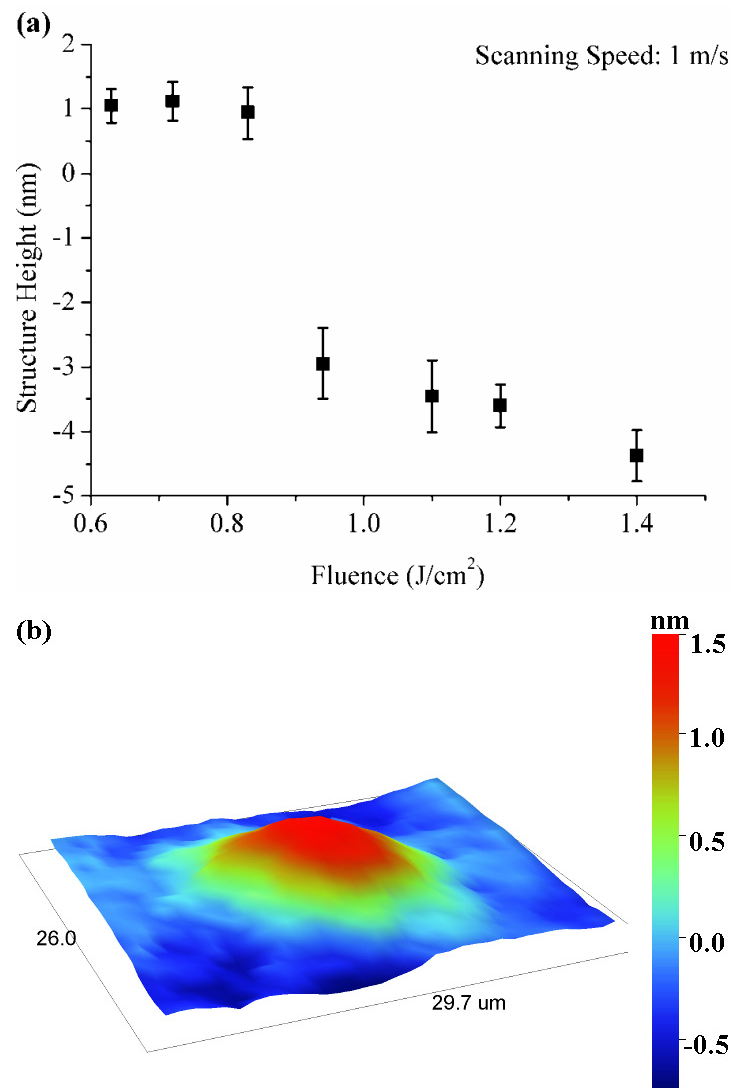


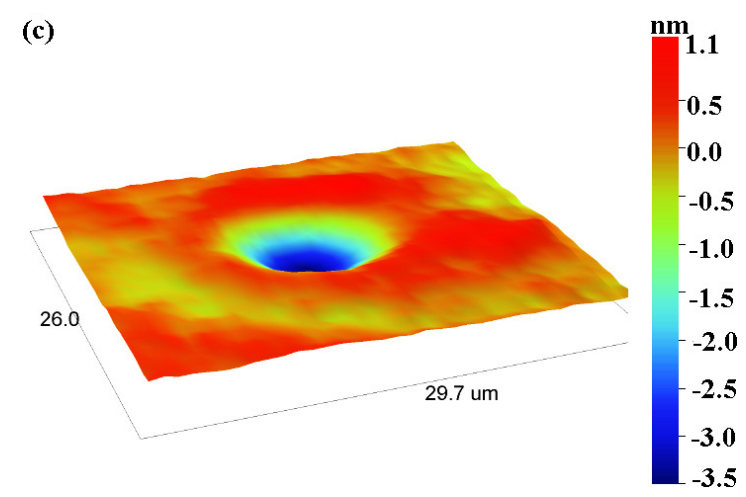

Figure 5 (a) Graph illustrating the change in height profile from nano-bumps to nano-holes as the laser fluence increases from $0.54 \mathrm{~J} / \mathrm{cm}^{2}$ to $1.4 \mathrm{~J} / \mathrm{cm}^{2}$. (b) Wyko image of nano-bump generated at a laser fluence of $0.72 \mathrm{~J} / \mathrm{cm}^{2}$, and (c) crater generated at a laser fluence of $0.94 \mathrm{~J} / \mathrm{cm}^{2}$.

Besides laser fluence, the scanning speed is another important system parameter affecting the process. It should be noted that we fixed the repetition rate to $30 \mathrm{kHz}$ and the scanning speed to $v=1 \mathrm{~m} / \mathrm{s}$; this corresponds to one pulse per spot. As the scanning speed changes, the number of pulses per spot will change and the final sample surface topography and period of the structures will vary accordingly. Figures 6 and 7 summarize the dependence of structure height and structure period as a function of scanning speed within a range from $0.8 \mathrm{~m} / \mathrm{s}$ to 3.0 $\mathrm{m} / \mathrm{s}$, at a fixed laser fluence of $0.72 \mathrm{~J} / \mathrm{cm}^{2}$ and a fixed repetition rate of $30 \mathrm{kHz}$. Within this scanning speed range structuring results in a uniform array of nano-bumps with a clearly defined height and period. At a scanning speed of $0.6 \mathrm{~m} / \mathrm{s}$, the number of pulses per spot is around 3 and the obtained structures become irregular and craters and nano-bumps are mixed and overlapped without clear spacing between individual spots. When the scanning speed decreases to $0.1 \mathrm{~m} / \mathrm{s}$, the number of pulses per spot increases to 16.5 and a dotted line of $12.05 \mu \mathrm{m}$ in width and $10 \mathrm{~nm}$ in depth is generated. As the scanning speed decreases further, line width and depth keep increasing.

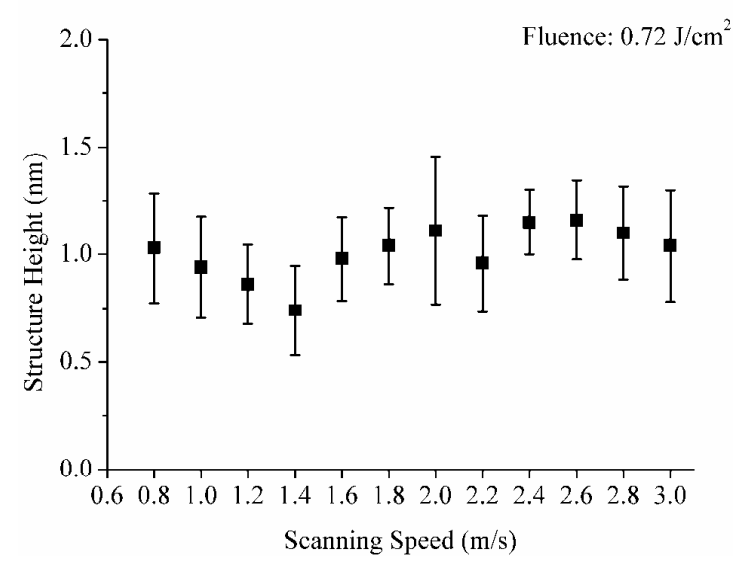

Figure 6. Nano-bumps height as a function of scanning speed 


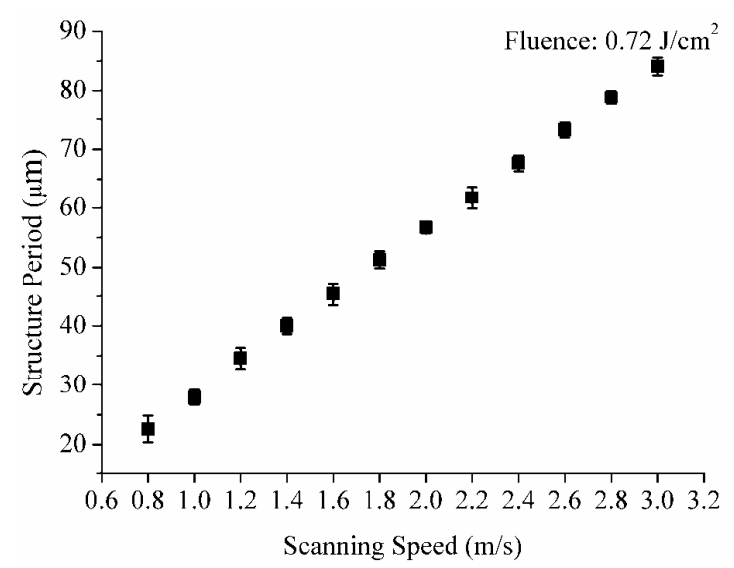

Figure 7. Nano-bumps period as a function of scanning speed

The scanning speed effect was further studied for other laser fluences. Figure 8 shows the dependence of structure (nano-bumps) height as a function of scanning speed at laser fluences of $0.54 \mathrm{~J} / \mathrm{cm}^{2}$ and $0.63 \mathrm{~J} / \mathrm{cm}^{2}$. It was noticed that for fluence values below $0.72 \mathrm{~J} / \mathrm{cm}^{2}$ and scanning speeds of 0.2 to $3.2 \mathrm{~m} / \mathrm{s}$, the surface was either unaffected (structure height of $0 \mathrm{~nm}$ ) or populated by nano-bumps (structure height $<1 \mathrm{~nm}$ ).

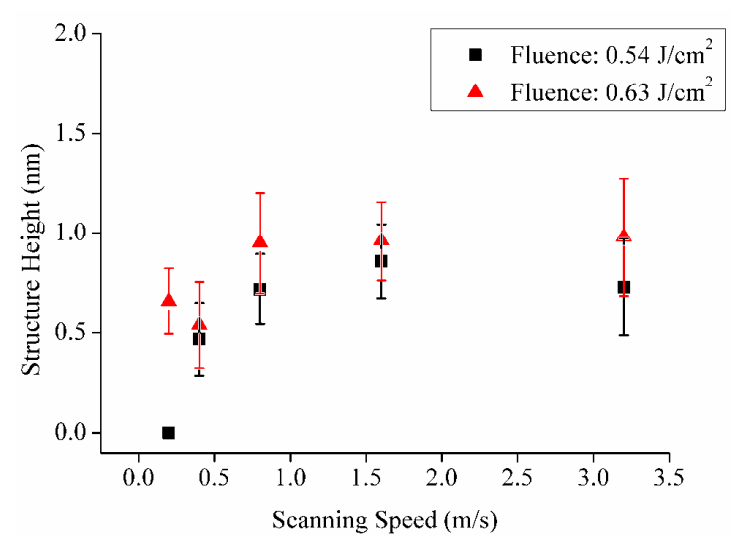

Figure 8. Variations of nano-bumps height versus scanning speed for laser fluences of $0.54 \mathrm{~J} / \mathrm{cm}^{2}$ and $0.63 \mathrm{~J} / \mathrm{cm}^{2}$.

On the other hand, as shown in figure 9, when the fluence is $0.72 \mathrm{~J} / \mathrm{cm}^{2}$ and the scanning speed is less than $0.4 \mathrm{~m} / \mathrm{s}$ craters with depths of a few nanometres (negative-value in height) cover the laser treated surface. The craters change to nano-bumps (height of around 1 nanometre) only when the scanning speed increases to $0.8 \mathrm{~m} / \mathrm{s}$. However, the crater-to-bump transition trend was not observed for slightly higher fluences of 0.83 and $0.94 \mathrm{~J} / \mathrm{cm}^{2}$, for which craters do not develop into 1-nm-height nano-bumps even if the scanning speed is increased. 


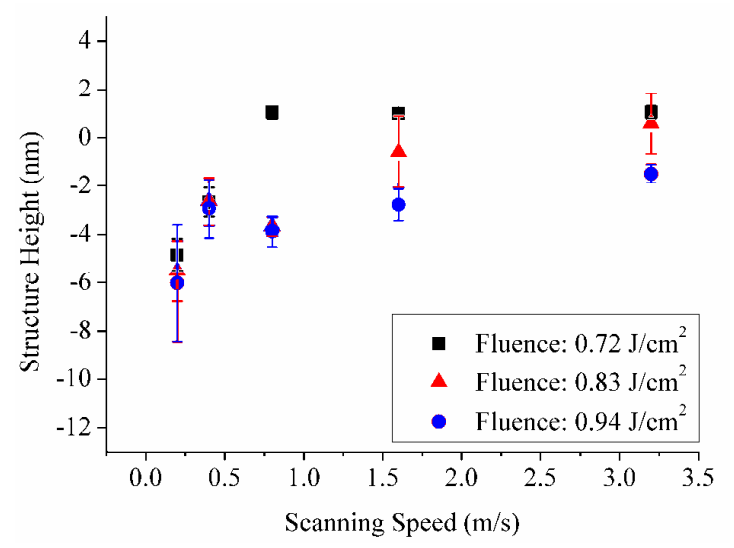

Figure 9. Variations of structure height versus scanning speed for laser fluences of $0.72 \mathrm{~J} / \mathrm{cm}^{2}, 0.83$ $\mathrm{J} / \mathrm{cm}^{2}$ and $0.94 \mathrm{~J} / \mathrm{cm}^{2}$.

3.2 Scanning electron microscopy (SEM) and energy-dispersive X-ray spectroscopy (EDX) analysis

Different computer designed patterns can be easily transferred to a silicon surface through the integrated galvanometer scanning system. Figure 10 shows SEM images of (a) a spiral pattern and (b) cross grids fabricated on a silicon surface using the following parameters: laser fluence of $0.95 \mathrm{~J} / \mathrm{cm}^{2}$, scanning speed of $1 \mathrm{~m} / \mathrm{s}$ and laser repetition rate of $30 \mathrm{kHz}$. These laser marks are made of nano-bumps. Clearly a strong contrast can be seen in the SEM image for the processed and non-processed regions. The irradiated areas exhibit the white halo which is typical for an amorphous film [6]. This suggests that the material could have gone through a phase transition from single-crystal to amorphous. 

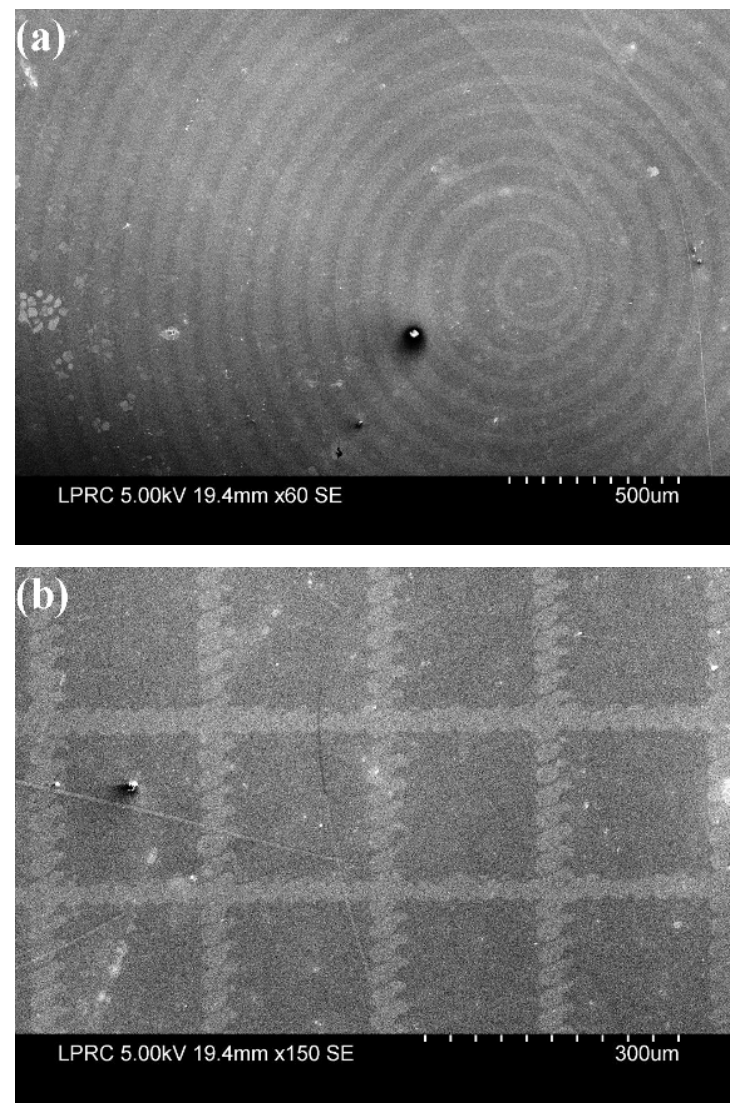

Figure 10. SEM images of laser marks on a crystalline silicon surface made of laser generated nanobumps at laser fluence of $0.95 \mathrm{~J} / \mathrm{cm}^{2}$, scanning speed of $1 \mathrm{~m} / \mathrm{s}$ and repetition rate of $30 \mathrm{kHz}$ : (a) spiral pattern, (b) cross grids.

SEM images of the craters were also analyzed to detect the presence of a possible amorphous layer when the fluence is above the ablation threshold. In figure $11 \mathrm{a}$ white region around the craters is observed, it follows the elliptical shape of the Gaussian beam, exhibits a 'ring' feature, and is similar to the reported laser amorphized morphologies in the literature [7, 8].

At a laser fluence of $1.14 \mathrm{~J} / \mathrm{cm}^{2}$, the craters are only a few nano-metres deep, and the rim around them is $\sim 0.5 \mathrm{~nm}$ high. Because of the Gaussian distribution of the beam, the energy fluence at the centre is sufficiently high to ablate the material. However, the surrounding white annulus could be explained by a phase transition due to lower laser energy delivered to this area. When the laser intensity is decreased the modified areas are smaller than the nominal laser spot. In our case this results in half the original size along the minor axis of the beam and hence the reduction in the structure diameter. 

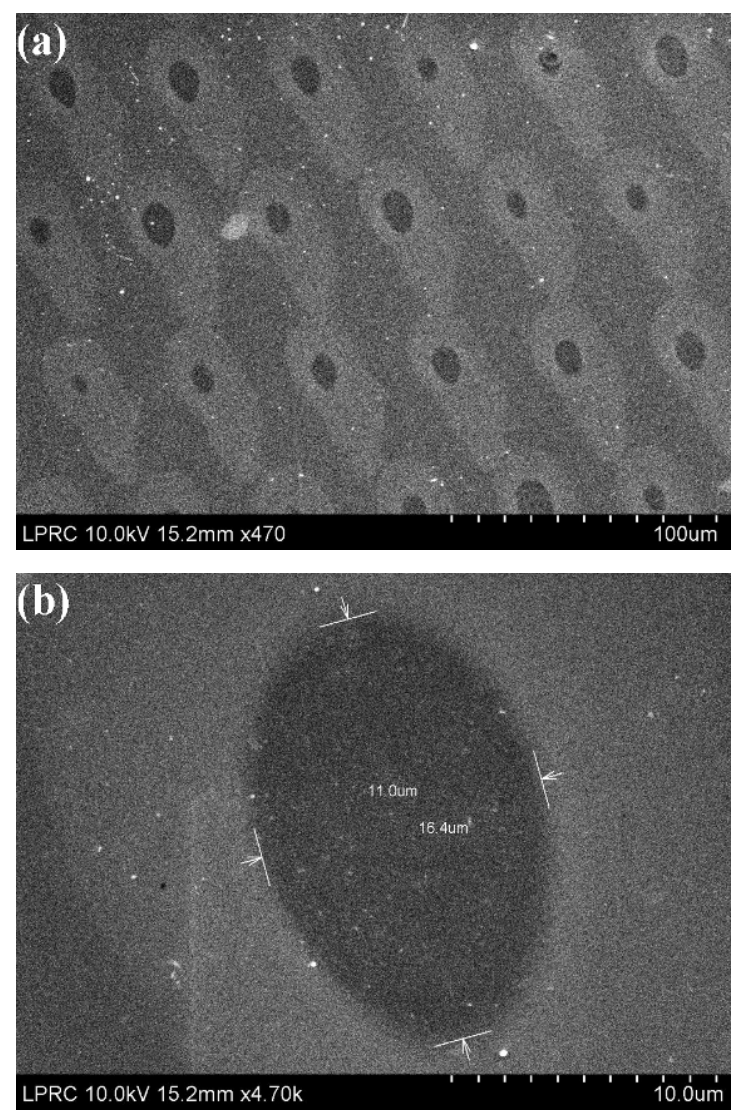

Figure 11. (a-b) SEM images of a laser processed silicon sample at a laser fluence of $1.14 \mathrm{~J} / \mathrm{cm}^{2}$, scanning speed of $2.0 \mathrm{~m} / \mathrm{s}$, frequency of $35 \mathrm{kHz}$ and a hatch distance of $0.07 \mathrm{~mm}$.

In order to further investigate the chemical composition of the laser generated patterns energy-dispersive X-ray spectroscopy (EDX) analysis was performed. According to the EDX results (shown in figure 12) no trace of oxygen was found in the samples which excludes oxidation from the process. The white regions in figure 10 and 11 are thus purely silicon in non single-crystalline states (either amorphous or poly-crystalline).

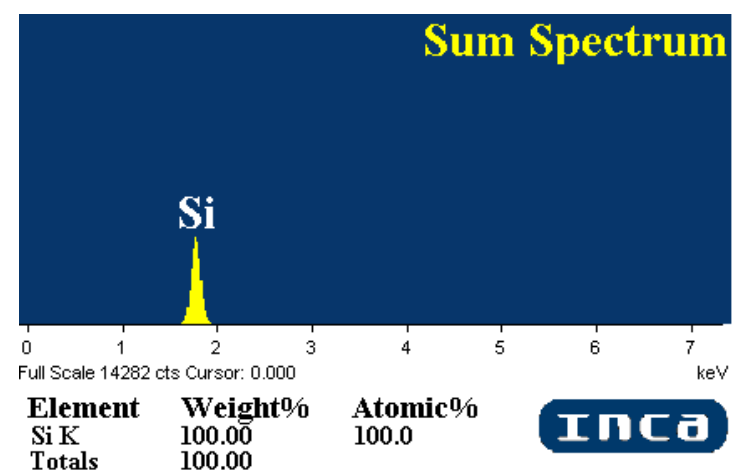

Figure 12. EDX spectrum of a laser generated nano-crater (shown in figure 11b). 


\subsection{Surface post-processing: Potassium Hydroxide (KOH) etch}

To further determine the possible phase-change of the laser processed patterns, we employed a chemical etching method. It has been reported that an amorphous layer on silicon can be used as an etch mask against $\mathrm{KOH}$ for micro/nano fabrication purposes [7, 9, 10]. Based on this, the samples exhibiting the $1 \mathrm{~nm}$ nano-bumps array where immersed in a $30 \% \mathrm{wt}$. $\mathrm{KOH}$ solution at $55^{\circ} \mathrm{C}$ for 90 seconds and under constant stirring. Immediately after this, they were rinsed with abundant deionised water to stop further etching.

The results of this post-processing step are shown in figure 13. The laser-generated nanobumps were not etched, while the non-treated regions were affected by the etchant. Thus, the laser processed areas masked the material against the typical effects of $\mathrm{KOH}$ in silicon which is readily etched in the $<100>$ plane [11].
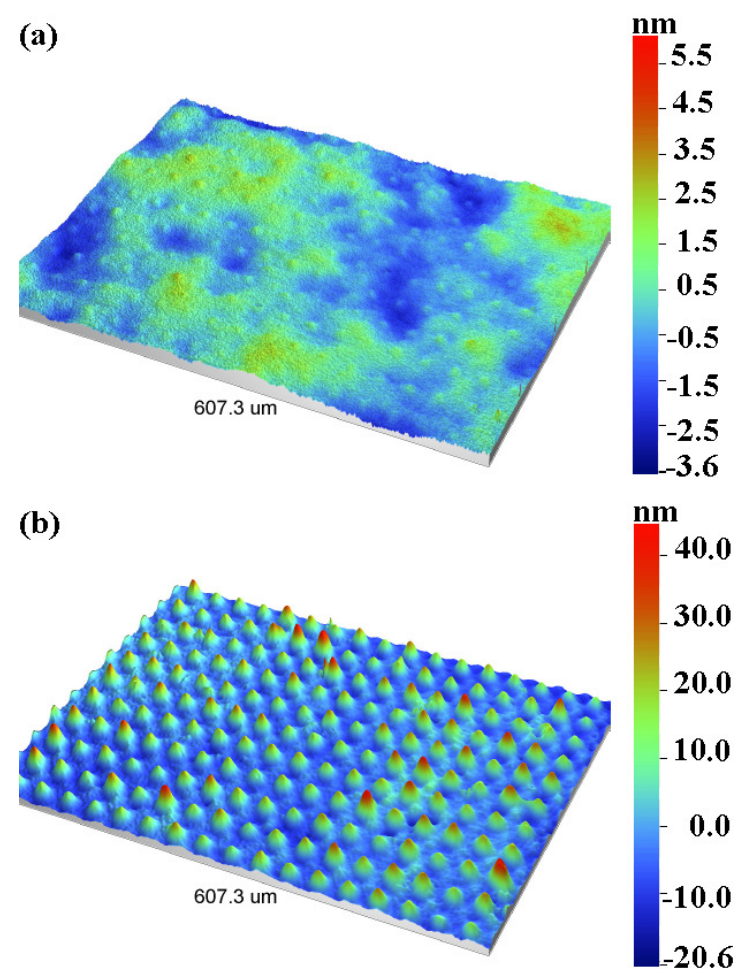

Figure 13. Wyko images of a laser-treated silicon sample exhibiting a uniform nano-bumps array, generated at (a) a laser fluence of $0.83 \mathrm{~J} / \mathrm{cm}^{2}, 30 \mathrm{kHz}, 1.2 \mathrm{~m} / \mathrm{s}$, and hatch distance of $0.05 \mathrm{~mm}$; (b) same surface after being immersed in a $\mathrm{KOH}$ solution at $55^{\circ} \mathrm{C}$ for 90 seconds.

The corresponding height profiles are presented in figure 14. It can be seen that after $\mathrm{KOH}$ etching, the nano-bumps height ascends to $\sim 28 \mathrm{~nm}$. This means that the etch ratio of processed region was almost 30 times lower than that of the nano-processed crystalline regions. This value agrees well with the result from Kawasegi et al. when they etched an amorphous Si layer formed by magnetron spattering [9]. Although Lam et al. [12] have suggested that at low fluences single-crystal Si could undergo a phase change to polycrystalline, this could be excluded in our case due to the fact that the etching rates for 
crystalline and poly-crystalline silicon are similar when they were exposed to $30 \%$ wt. $\mathrm{KOH}$ [13].
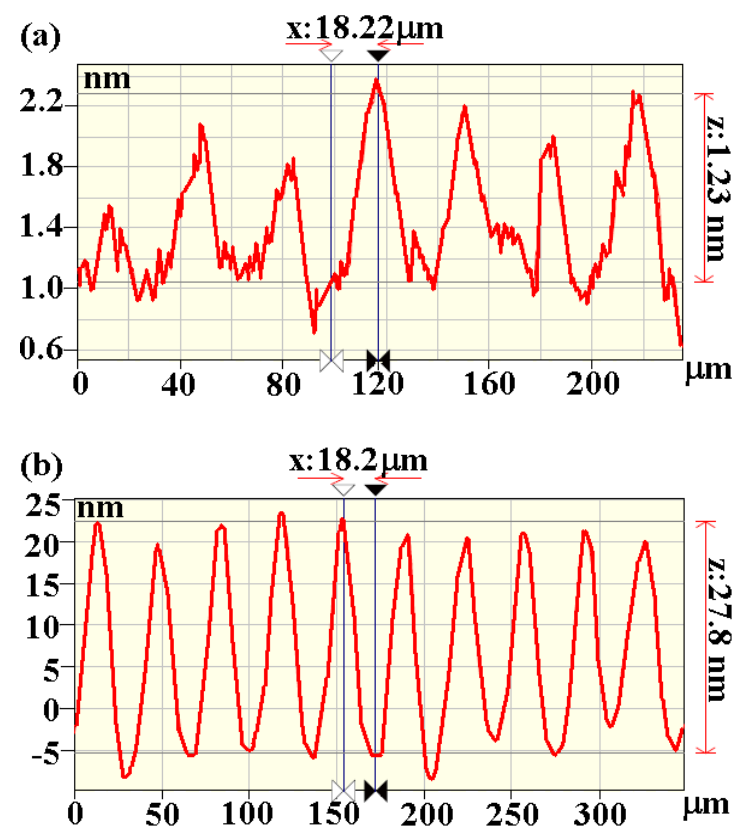

Figure 14. Height profiles of laser processed nano-bumps array at (a) a fluence of $0.83 \mathrm{~J} / \mathrm{cm}^{2}$ and scanning speed of $1.2 \mathrm{~m} / \mathrm{s}$ (height is $\sim 1.2 \mathrm{~nm}$ ) ; (b) same surface after being immersed in a $\mathrm{KOH}$ solution at $55^{\circ} \mathrm{C}$ et for 90 seconds (height is $\sim 28 \mathrm{~nm}$ ).

For the nano-bumps with the lowest height (around $1 \mathrm{~nm}$ ), obtained with a laser fluence of $0.72 \mathrm{~J} / \mathrm{cm}^{2}$, we used a longer etching time (120 seconds) to enhance the etch depth. Again the laser generated nano-bumps remained on the surface and the surrounding non-processed areas were etched much quicker (figure 15b) resulting in a bump height of around $27 \mathrm{~nm}$. In this case it was possible to distinguish the elliptical shape of the Gaussian beam which was made visible thanks to a longer exposure to the wet etchant. When the etching time was further extended, the nano-bumps started to diminish in height and eventually disappeared from the surface. This indicates that the laser-modified material was entirely removed and could not longer be used as an etch-stop mask. 


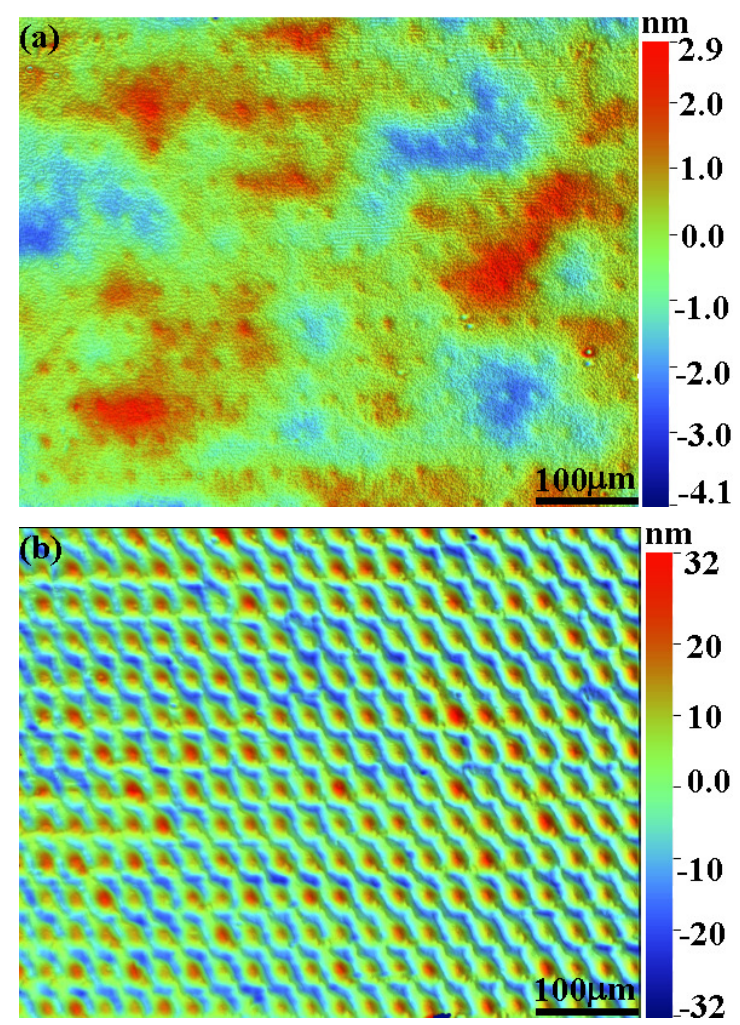

Figure 15. Wyko images of a laser-treated silicon sample exhibiting a uniform nano-bumps array, generated at (a) a laser fluence of $0.72 \mathrm{~J} / \mathrm{cm}^{2}$, repetition rate of $30 \mathrm{kHz}$, scanning speed of $1.0 \mathrm{~m} / \mathrm{s}$, and hatch distance of $0.04 \mathrm{~mm}$; (b) same surface after being immersed in a $\mathrm{KOH}$ solution at $55^{\circ} \mathrm{C}$ for 120 seconds.
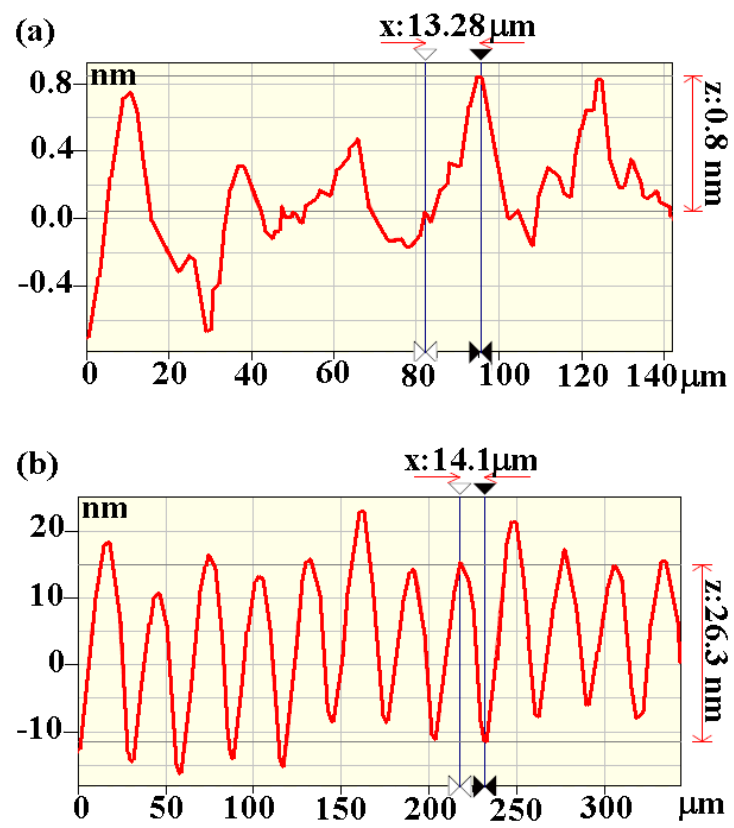

Figure 16. Height profile of nano-bumps array at (a) a fluence of $0.72 \mathrm{~J} / \mathrm{cm}^{2}$ and scanning speed of 1.0 $\mathrm{m} / \mathrm{s}$ (height is $\sim 0.8 \mathrm{~nm}$ ) ; (b) same surface after being immersed in a $\mathrm{KOH}$ solution at $55^{\circ} \mathrm{C}$ for 120 seconds (height is $\sim 26 \mathrm{~nm}$ ). 


\subsection{Wettability Characteristics}

The presented nano-structures on Si changed the surface wettability of the material. In our study we observed that vapour condenses into water drops of different size depending on the processed and non-processed areas. This vapour condensation effect helps the observer to easily recognize the 'optically invisible' nano-bumps which otherwise can only be detected by a white light interferometer or atomic force microscope. Figure 17 shows several examples of such characteristic wetting behaviour. The spiral rings and letters "LPRC" were scribed over the silicon surface. The contour of the letters was patterned with the $1 \mathrm{~nm}$ high bumps as previously described. Following their immersion in warm vapour, drops of clearly larger size (13-23 $\mu \mathrm{m})$ covered the nano-bumps while smaller drops $(5-7 \mu \mathrm{m})$ dwelled in the unmarked areas. Such difference in drop size is responsible for the change in visibility of the markings. Clearly, the laser marked areas are more hydrophilic exhibiting a larger contact line for the liquid and solid interface (lower liquid/solid contact angle). The observed change in the wetting characteristics of laser marked surfaces depends also on the ambient and substrate temperatures because this permits condensation to occur. The larger such difference is, the more perceptible the invisible markings effect is expected to be.
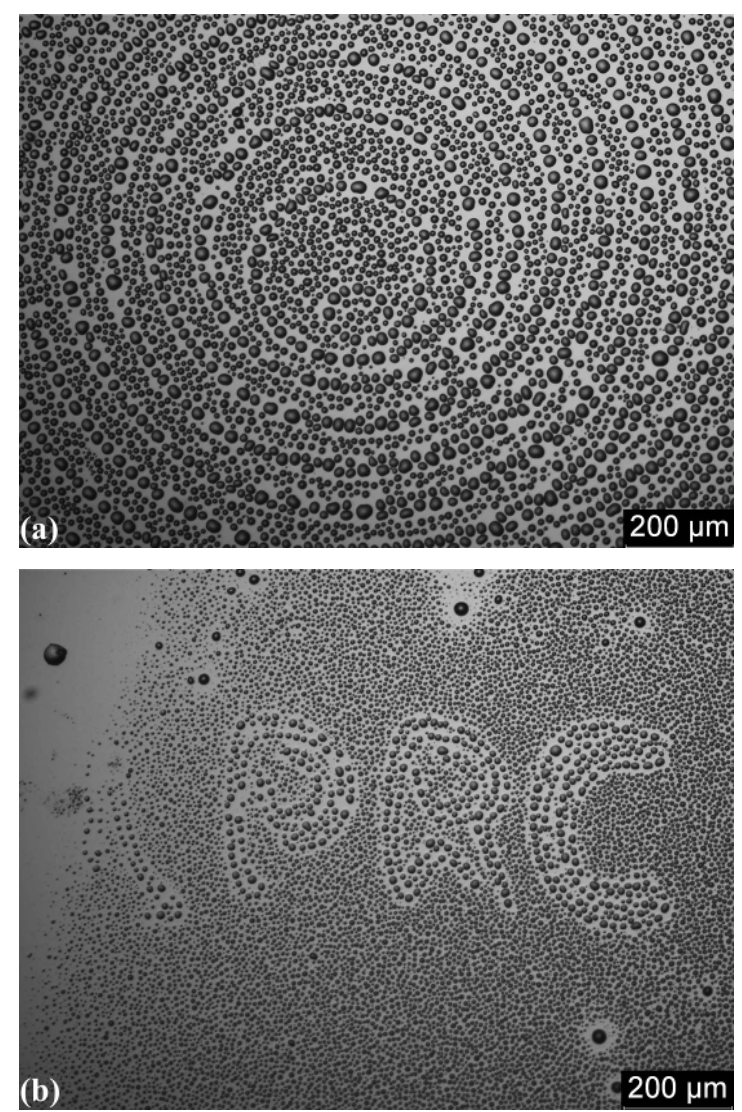

Figure 17. Recognition of laser marks after being exposed to warm vapour. The difference in water drops at the micro scale allows the viewer to see by means of an optical microscope: (a) a spiral ring, (b) "LPRC” letters. 


\section{Discussion}

\subsection{Wetting behaviour before and after laser processing}

Crystalline silicon will inherently grow a native oxide layer (1-2 nm high) after polishing, which makes the material more susceptible to surface contamination [14]. Since surface wettability is mainly influenced by the nature and arrangement of the top surface atomic layers [15], a measured contact angle of $\theta=58^{\circ}$ in our non-treated samples is the result of the interaction of water molecules with $\mathrm{Si}-\mathrm{O}$ bonds on the top surface. This is consistent with the reported values of Dixit et al. [16].

Considering that the laser processing was done at air conditions, the observed reduction in contact angle at the micro-scale in the treated samples might have occurred due to the introduction of more Si-OH bonds (silanol groups). This could be explained by a strong interaction of the water molecules in the ambient environment with the dangling bonds from the laser-modified amorphous material.

These silanol groups will make the surface layer more complex because they can permute to form a larger number of different chemical species which will exhibit distinct hydrophilic properties [17]. The chemical behaviour of more silanols created in the surface of the material during the nano-structure generation and possible phase-change transition, may clarify the noticeable difference in wettability seen on the marks at the micro-scale.

Laser surface treatment has been used by other authors to modify the wettability and adhesion characteristics of silicon [18]. By employing the $4^{\text {th }}$ harmonic of a Nd:YAG pulsed laser $(\lambda=266 \mathrm{~nm})$ to irradiate a silicon sample, they noticed a decrease in contact angle and a change in the surface chemical composition of the material. A laser power of 0.8 to $0.9 \mathrm{~W}$, and a scanning speed of $100 \mu \mathrm{m} / \mathrm{s}$ led to a decrease in contact angle from $\theta=47^{\circ}$ (before laser processing) down to $\theta=0^{\circ} \sim 22^{\circ}$ (after laser processing). Energy dispersive X-ray analysis enabled the authors to determine the relative content of oxygen after laser treatment and $\mathrm{X}$ ray photoelectron spectroscopy confirmed the presence of (-OH-) bonds in large proportions compared to other chemical species. Thus, it was suggested that such oxygen-enriched surface enhanced the hydrophilic behaviour of the samples and hence the improvement of the adhesion forces on the surface. It was observed as well that after laser treatment the contact angles were inversely proportional to the surface roughness, which also played a role in the increment of the work of adhesion values. It has to be reminded that such reported contact angle values for the laser treated and untreated surfaces were measured at the macro-scale by the sessile drop method. These values might vary from the actual contact angles of water drops condensing at the micro-scale in a Si surface, as seen in the wetted laser-marks reported in our paper (figure 17). 
In the present study, the effect of surface roughness on the contact angle measurements is deemed as negligible. This is because in our samples the magnitude of the roughness is too small ( $<40 \AA$ ) to affect the wetting behaviour of the laser treated surfaces. This is in contrast to many of the micro and nano-structured surfaces studied by other authors [19-25] wherein the roughness is large enough to affect the surface contact angles. An example of how the wettability of a surface can be modified by laser micro and nano-structuring was demonstrated by Zorba et al. [26]. They successfully created a wettability gradient in a crystalline Si surface using a femto-second laser. When the authors varied the fluence, different microstructure morphologies (e.g. micro-ripples and micro-spikes) altered the wetting properties of the material and made it more hydrophobic. At laser fluences above 1 $\mathrm{J} / \mathrm{cm}^{2}$, they observed that nano-metre features covered the micro-features, increasing the overall roughness but contributing in a lesser way to the hydrophobic behaviour of the samples. Although a disordered Si layer (few nanometres thick) was identified in their laserprocessed samples, micro-structuring was considered to be the main mechanism behind the high contact angles obtained.

In our current investigation it is suggested that anisotropic wetting has been made possible due to a modification in the arrangement of atoms in the first layers of the material, apparently when it changes from crystalline to amorphous. It has also been considered that the aspect ratio of the nano-bumps is too low $\left(5(10)^{-5}\right)$ in order to alter the wetting properties at the surface. Besides helping identify the low-aspect marks, this wetting behaviour could be employed in the preparation of very low-aspect micro-fluidic channels. An example of this is shown in figure 18 wherein it can be appreciated how long water drops tend to elongate and spread along the laser-patterned areas.

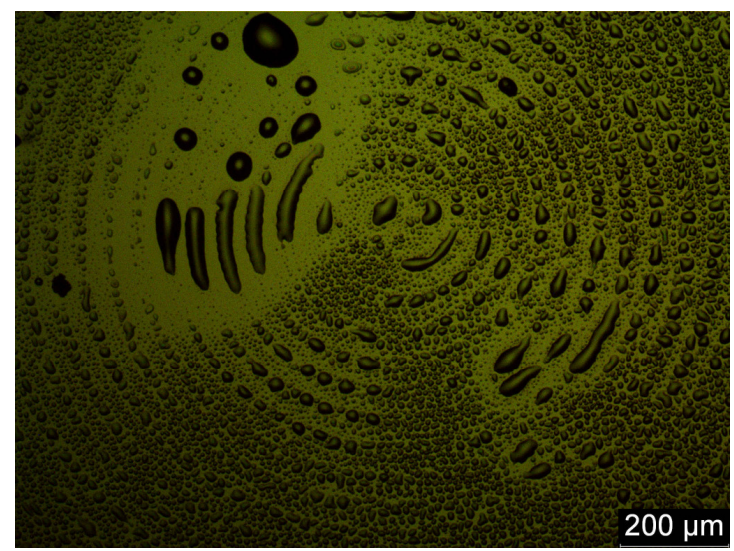

Figure 18. Elongated water drops on the location of the laser marks show how these could be used as low-aspect micro-fluidic channels. 


\subsection{Surface modification}

The laser fluences used in this study had very unique effects on the material (i.e. laserinduced amorphization). Acknowledged as interactions below the ablation threshold [27], such effects are noticeable in different ways: surface morphology and microstructure, presence of defects, and depletion of components. In the present case, surface morphology (i.e. first signs of nano-bump formation) became an outcome when the amorphization threshold was visibly identified at a laser fluence of $0.5 \mathrm{~J} / \mathrm{cm}^{2}$. With increased fluence, at 0.72 $\mathrm{J} / \mathrm{cm}^{2}$ the nano-bumps are at their highest $(\sim 1.2 \mathrm{~nm})$ and it is not until $0.83 \mathrm{~J} / \mathrm{cm}^{2}$ that the ablation threshold takes place characterized by a decline in nano-bump height $(<0.9 \mathrm{~nm})$ and the generation of craters accompanied by an outer rim (see figures 1 and 3 ).

The laser-induced phase transition from the single-crystalline to the amorphous state in Si by a nanosecond laser was first reported by Tsu et al. [6]. They produced a thin amorphous layer by employing the fourth harmonic of an Nd:YAG laser $(\lambda=266 \mathrm{~nm}, \tau=10 \mathrm{~ns})$. By electron diffraction patterns they noticed that such layer was characterized by a white colour and had a slight thickness variation above the original surface. The authors concluded that such a phase change occurs when melted $\mathrm{Si}$ is rapidly cooled down without an opportunity for material recrystallization.

The findings from the current study suggest that the reported fluence values resulted in a laser-induced phase-change in the material from crystalline to amorphous. Whenever low energies are applied to the substrate by short pulses, heating of a thin surface layer results in a shallow liquid depth and rapid re-solidification of the material does not allow for epitaxial regrowth [28-31]. This implies that $\mathrm{Si}$ atoms cannot rearrange again in an ordered, crystalline form. Instead, a disordered arrangement of $\mathrm{Si}$ atoms (some of them having dangling bonds) results in an amorphous layer. Liquid/solid interface velocities must be sufficiently high to promote amorphization from the melt and avoid crystal nucleation with typical values $>15$ $\mathrm{m} / \mathrm{s}$ for $<100>\mathrm{Si}$ [31-33] which are in agreement with the laser-fluence range used in this study.

Considering this, the nano-bumps are generated when the laser intensity distribution is controlled in such a way that only the central part of the beam is above the material's amorphization threshold. As the laser intensity increases above the ablation threshold, craters are formed at the centre of the beam while amorphous rims at their edges are created due to the Gaussian-profiled intensity distribution.

\section{Conclusion}

We have reported the generation of nano-bumps of less than $2 \mathrm{~nm}$ in height on Si by a diode pumped Nd: $\mathrm{YVO}_{4}$ laser system at 30,000 bumps per second. The formation of such bumps alters the wettability properties of the substrate. This effect is apparent as a difference in 
water droplet size when vapour condensation occurs on top of the material. By means of such difference, the laser marks made of such bumps can be visible without the use of complex equipment. This marking technique is debris-free, does not introduce contamination of any form to the material and could be implemented into practice straight away. X-ray photoelectron spectroscopy (XPS) analysis needs to be done in the future to determine the precise contents (i.e. at levels below one monolayer) regarding all the elements present on the surface samples before and after processing. This will give a better understanding of the wetting and de-wetting processes occurring on the surface of the laser marks. Also the technique could be explored for different applications including micro-fluidics and bioengineering. 


\section{References}

1. G. Bo: in Proc. SPIE - Int. Soc. Opt. Eng. (USA), 610601-1 (San Jose, USA 2006)

2. J. Scaroni, T. McKee: Solid State Technol. 40, 245-251 (1997)

3. T. Chiba, R. Komura, A. Mori: Jpn. J. Appl. Phys.1 39, 4803-10 (2000)

4. M. Weingartner, R. Elschner, O. Bostanjoglo: Appl. Surf. Sci. 138, 499-502 (1999)

5. M. Himmelbauer, E. Arenholz, D. Baeuerle, K. Schilcher: Appl. Phys. A-Mater. A63, 337-9 (1996)

6. R. Tsu, R. T. Hodgson, T. Teh Yu, J. E. Baglin: Physical Review Letters 42, 13568 (1979)

7. A. Kiani, K. Venkatakrishnan, B. Tan: Optics Express 17, 16518-16526 (2009)

8. Y. Izawa, Y. Setuhara, M. Hashida, M. Fujita, Y. Izawa: Japanese Journal of Applied Physics, Part 1: Regular Papers and Short Notes and Review Papers 45, 5793-5794 (2006)

9. N. Kawasegi, N. Morita, S. Yamada, N. Takano, T. Oyama, K. Ashida: Nanotechnology 16, 1411-1414 (2005)

10. N. Kawasegi, N. Morita, S. Yamada, N. Takano, T. Oyama, K. Ashida, J. Taniguchi, I. Miyamoto: JSME International Journal, Series C (Mechanical Systems, Machine Elements and Manufacturing) 49, 583-9 (2006)

11. H. Seidel, L. Csepregi, A. Heuberger, H. Baumgartel: Journal of the Electrochemical Society 137, 3612-26 (1990)

12. Y. C. Lam, H. Y. Zheng, R. T. Tjeung, X. Chen: Journal of Physics D: Applied Physics 42, 042004 (4 pp.) (2009)

13. K. R. Williams, K. Gupta, M. Wasilik: Journal of Microelectromechanical Systems 12, 761-78 (2003)

14. M. C. Gomes, A. C. Fernandes, B. S. Almeida, R. M. Almeida: J. Mater. Sci. 30, 3893-6 (1995)

15. J. Lawrence, L. Li: Laser Modification of the Wettability Characteristics of Engineering Materials (Professional Engineering Publishing Suffolk 2001)

16. P. Dixit, C. Xiaofeng, M. Jianmin, R. Preisser: Thin Solid Films 516, 5194-200 (2008)

17. R. R. Thomas, F. B. Kaufman, J. T. Kirleis, R. A. Belsky: J. Electrochem. Soc. 143, 643-8 (1996)

18. K. Dong-Yong, L. Kyoung-cheol, L. Cheon: in Proc. SPIE - Int. Soc. Opt. Eng. (USA), 66-70 (Munich, Germany 2003)

19. C. Yang, U. Tartaglino, B. N. J. Persson: Physical Review Letters 97, 116103-1 (2006)

20. N. A. Patankar: Langmuir 20, 8209-8213 (2004)

21. D. Oner, T. J. McCarthy: Langmuir 16, 7777-82 (2000)

22. L. Feng, S. Li, Y. Li, H. Li, L. Zhang, J. Zhai, Y. Song, B. Liu, L. Jiang, D. Zhu: Advanced Materials 14, 1857-1860 (2002)

23. Y. Wu, H. Sugimura, Y. Inoue, O. Takai: Chemical Vapor Deposition 8, 47-50 (2002)

24. Y. T. Cheng, D. E. Rodak, C. A. Wong, C. A. Hayden: Nanotechnology 17, 1359$62(2006)$

25. M. Miwa, A. Nakajima, A. Fujishima, K. Hashimoto, T. Watanabe: Langmuir 16, 5754-60 (2000)

26. V. Zorba, L. Persano, D. Pisignano, A. Athanassiou, E. Stratakis, R. Cingolani, P. Tzanetakis, C. Fotakis: Nanotechnology 17, 3234-8 (2006) 
27. D. Bäuerle: Laser Processing and Chemistry (Springer-Verlag Heidelberg 2000)

28. A. Miotello, L. F. Dona'Dalle Rose: Physics Letters A 98A, 367-70 (1983)

29. J. Jia, M. Li, C. V. Thompson: Applied Physics Letters 84, 3205-3207 (2004)

30. P. L. Liu, R. Yen, N. Bloembergen, R. T. Hodgson: Applied Physics Letters 34, 864-6 (1979)

31. A. G. Cullis, H. C. Webber, N. G. Chew, J. M. Poate, P. Baeri: Physical Review Letters 49, 219-22 (1982)

32. M. O. Thompson, J. W. Mayer, A. G. Cullis, H. C. Webber, N. G. Chew, J. M. Poate, D. C. Jacobson: Physical Review Letters 50, 896-9 (1983)

33. A. Polman, P. A. Stolk, D. J. W. Mous, W. C. Sinke, C. W. T. Bulle-Lieuwma, D. E. W. Vandenhoudt: Journal of Applied Physics 67, 4024-35 (1990) 